\title{
Prolonged Overall Treatment Time Negatively Affects the Outcomes of Stereotactic Body Radiotherapy for Early-Stage Non-Small Cell Lung Cancer: A Propensity Score-Weighted, Single-Center Analysis
}

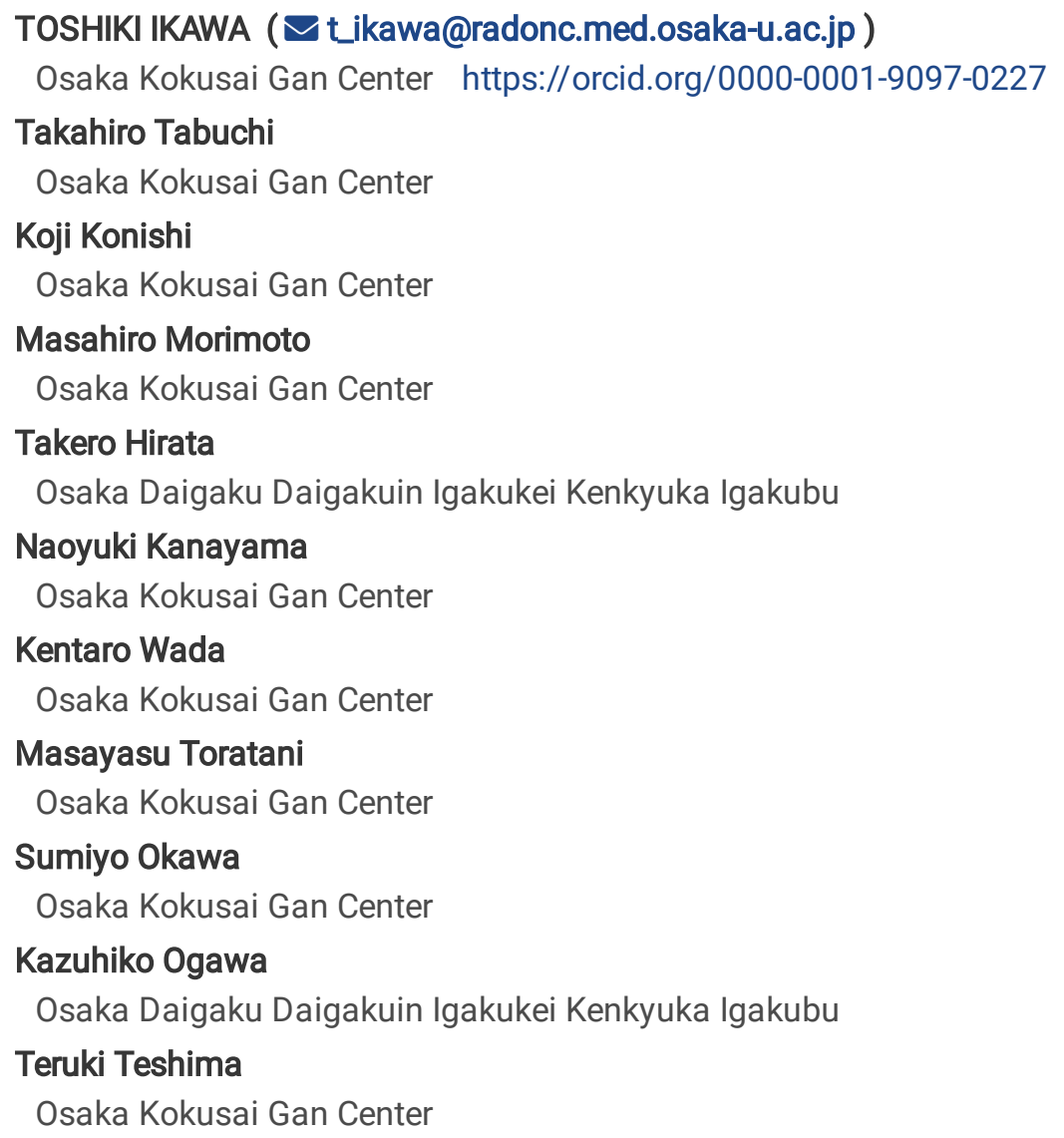




\section{Abstract}

Background

Previous studies have reported conflicting results for the effect of overall treatment time (OTT) on tumor control with stereotactic body radiotherapy (SBRT) for early-stage non-small cell lung cancer (NSCLC). To examine this effect, we conducted a propensity score-weighted, retrospective, observational study at a single institution.

Methods

We analyzed the data of 200 patients with early-stage NSCLC who underwent SBRT (48 Gy in 4 fractions) at our institution between January 2007 and October 2013. Patients were grouped into consecutive (OTT $=4-5$ days, $n=116$ ) or non-consecutive treatment groups (OTT $=6-10$ days, $n=84$ ). The outcomes of interest were local control and overall survival. The Cox regression model was used with propensity score and inverse probability of treatment weighting.

Results

The median OTTs in the consecutive and non-consecutive groups were 4 and 6 days, respectively. The 5-year local control and overall survival rates in the consecutive group vs. non-consecutive group were $86.3 \%$ vs. $77.2 \%$ and $55.5 \%$ vs. $51.8 \%$, respectively. After propensity score-weighting, consecutive SBRT was associated with positive local control (adjusted hazard ratio $0.30,95 \%$ confidence interval $0.14-0.65 ; p=0.002$ ) and overall survival benefits (adjusted hazard ratio $0.56,95 \%$ confidence interval $0.34-$ $0.91 ; p=0.019)$.

Conclusions

Prolonged OTT negatively affected the outcomes of patients with early-stage NSCLC treated with SBRT. To our knowledge, this is the first study to show that in patients with early-stage NSCLC treated with the same dose-fractionation regimen, consecutive SBRT has a more beneficial effect on tumor control than does non-consecutive SBRT.

\section{Introduction}

Stereotactic body radiotherapy (SBRT) or stereotactic ablative radiotherapy allows accurate delivery of very high radiation doses in a small number of fractions at an appropriate target volume using highly conformal radiotherapy planning, respiratory motion management, and daily image guidance [1,2]. Currently, SBRT is the primary treatment modality with excellent local control (LC) and low toxicity rates in patients with inoperable early-stage non-small cell lung cancer (NSCLC) and in patients who refuse surgery [2-5].

The optimal dose-fractionation schedule of SBRT for early-stage NSCLC to maximize tumor control and minimize toxicity has not been determined. The dose-fractionation schedule comprises the total dose, number of fractions, and overall treatment time (OTT). Several studies have shown that LC was better in patients treated with a biologically effective dose (BED) using an a/ $\beta$ ratio $=10$ Gy (BED10) of at least 100-105 Gy than in patients treated with less than 100-105 Gy [6-9]; BED estimates the biological effects of different dose-fractionation schemes on both tumor and normal tissue [10]. Conversely, few studies have reported the influence of OTT on SBRT outcomes in early-stage NSCLC, and their results were inconsistent [6, 11-13]. For example, Kestin et al. [6] demonstrated that a shorter treatment time ( $\leq 10$ days) was associated with better LC in a retrospective study including 483 patients who underwent SBRT for NSCLC at 5 institutions. In contrast, Samson et al. [11] retrospectively analyzed the data of 245 patients from two facilities who were treated with SBRT for CT1-2 NSCLC but did not observe an association between the treatment schedule ( $\leq 7 v s .>7$ days) and LC and overall survival (OS). However, these studies included several dosefractionation regimens. To overcome this limitation, we need to directly compare the influence of OTT on tumor control.

Therefore, we conducted a retrospective, observational study in patients with early-stage NSCLC who underwent SBRT with the same dose-fractionation regimen.

\section{Materials And Methods}




\section{Patients}

We identified 222 patients who received SBRT for primary lung cancer at our institution between January 2007 and October 2013. The inclusion criteria were (1) presence of newly diagnosed primary NSCLC with or without biopsy confirmation, regardless of prior treatment for lung cancer; (2) clinical T1-3NOMO (UICC TNM classification, $7^{\text {th }}$ edition); (3) tumor diameter less than $5 \mathrm{~cm}$; (4) received SBRT with $48 \mathrm{~Gy}$ in 4 fractions; and (5) follow-up time of at least 6 months. The exclusion criteria were patients with cytologically or histologically diagnosed small-cell lung cancer and those who received other dose fractionation regimens or adjuvant chemotherapy. Twenty-two patients were excluded, and 200 patients who met our inclusion criteria were enrolled.

This retrospective study was approved by our institutional review board (approval number 19164). All patients provided written informed consent for use of their data in clinical research before the administration of SBRT and had the opportunity to opt-out of the study.

\section{Treatment procedures}

All patients were immobilized with the BodyFix double-vacuum immobilization system (Medical Intelligence, Schwabmuenchen, Germany) and observed using four-dimensional computed tomography (CT). An internal target volume (ITV) was determined using four-dimensional CT images encompassing the gross tumor volumes (GTVs) in all respiratory phases. A planning target volume (PTV) was generated by expanding the ITV by $5-8 \mathrm{~mm}$ in all directions. A total dose of $48 \mathrm{~Gy}$ in 4 fractions was prescribed at the isocenter using 6-9 non-coplanar static conformal beams with a $5 \mathrm{~mm}$ multi-leaf collimator margin. All treatment plans were generated using the Eclipse treatment planning system (Varian Medical Systems, Palo Alto, CA, USA). The radiation doses before January 2009 were calculated using a pencil beam algorithm with an inhomogeneity correction and thereafter with an analytical anisotropic algorithm. Image guidance before September 2007 was based on bony anatomy matched with orthogonal $\mathrm{kV}$ imaging and thereafter, tumor matching with online three-dimensional cone-beam CT imaging was used. All treatments were delivered using a linear accelerator (Clinac 23EX, Varian Medical Systems, Palo Alto, CA, USA).

\section{Patient follow-up and evaluation of local failure}

Follow-up examinations after SBRT typically consisted of a chest CT every 3 months for 1 year, and thereafter, every 6 months. When relapse was suspected, ${ }^{18} \mathrm{~F}$-fluorodeoxyglucose-positron emission tomography-CT ( ${ }^{18} \mathrm{~F}$-FDG-PET/CT) was performed. Local failure was defined as recurrence within $1 \mathrm{~cm}$ of the PTV as described by the Radiation Therapy Oncology Group (RTOG) 0236 trial [3] and diagnosed using biopsy confirmation of viable carcinoma or the accumulation of FDG to maximum standardized uptake value (SUVmax) $\geq 5.0$ or the pre-treatment SUVmax [14]. When these examinations were not feasible, local failure was diagnosed based on the presence of high-risk CT features as proposed by Huang et al. [15] In patients who were not followed up in person, local failure was evaluated based on information from their new physicians.

\section{Outcomes}

We grouped patients into consecutive (OTT $=4$ or 5 days, $n=116$ ) or non-consecutive treatment groups (OTT $=6-10$ days, $n=$ 84) (i.e., in the consecutive group, SBRT was administered within a calendar week, whereas, in the non-consecutive group, SBRT was administered over two calendar weeks with a treatment-break because of the weekend). The primary and secondary outcomes of interest were LC and OS across the two groups. We performed all analyses at the patient level and restricted the follow-up period to the first 5 years after treatment. LC was defined as the time from the start of SBRT to the date of local failure. OS was defined as the time from the start of SBRT to the date of death from any cause.

\section{Statistical analyses}

The differences in baseline characteristics between the two groups were assessed using the Fisher's exact test or chi-squared test. To account for the imbalance of baseline covariates between the two groups, we performed a propensity score (PS) analysis using the inverse probability of treatment weighting (IPTW). PS values were estimated from covariates using multivariable logistic regression and plotted as histograms. The concordance statistic (c-statistic), a measure of goodness of fit in logistic regression, was used to test the appropriateness of the model. Covariate balance was assessed using a standardized mean difference 
approach. A standardized mean difference of less than 0.10 for a given covariate was considered as an acceptable balance. Unadjusted LC and OS curves were shown using the Kaplan-Meier method and compared with the log-rank test, and the corresponding hazard ratios (HRs) were estimated. Adjusted LC and OS curves were shown using the Cox proportional hazards model with PS-weighting, and the adjusted HRs were estimated. Furthermore, to account for the residual covariate difference after PS weighting, direct covariates-adjusted survival curves [16] with PS-weighting were generated using the covariates that we used to estimate PS, and the corresponding adjusted HRs were estimated. We performed a sensitivity analysis comparing 4 days of consecutive treatment with 6-10 days of non-consecutive treatment (i.e., excluding patients treated with an OTT of 5 days) to validate the robustness of the results.

All statistical tests were two-sided, and a p-value of less than 0.05 was considered statistically significant. All analyses were performed using R version 3.5.3 (R Foundation for Statistical Computing, Vienna, Austria) or SAS version 9.4 (SAS Institute Inc., Cary, NC, USA).

\section{Results}

\section{Patient characteristics and propensity score weighting}

The typical treatment schedules for each group are shown in Fig. 1. In the consecutive group, treatment breaks of 1 day occurred in 9 patients because of public holidays or machine maintenance. In the non-consecutive group, treatment breaks of 2-6 days occurred in 73 patients because of the weekend, public holidays, or machine maintenance, in 9 patients because of every-otherday SBRT based on the treatment protocol, and in 2 patients because of personal reasons. The median OTT in the consecutive group was 4 days (range $=4-5$ days), and approximately $90 \%(n=107)$ of the patients received SBRT over 4 days. In the nonconsecutive group, the median OTT was 6 days (range $=6-10$ days), and approximately $70 \%(n=56)$ of the patients received SBRT over 6 days (Additional file 1: Fig. S1).

Baseline characteristics of eligible patients, stratified by consecutive vs. non-consecutive treatment, are shown in Table 1. A significant difference was observed in the calendar period of treatment $(p<0.001)$. The use of non-consecutive SBRT was more frequent in 2009-2010 and 2011-2013 than in 2007-2008 ( $p<0.001$ and $p=0.005$, respectively). The standardized mean differences of unweighted comparisons significantly differed in all covariates except for tumor location (Table 1). The distributions of the estimated PS and c-statistic are shown in Additional file 1: Fig. S2. After PS weighting, the standardized mean difference for all covariates was confirmed to be less than 0.10 , which indicated that the distribution of all covariates was adequately balanced (Table 1).

\section{Outcomes and sensitivity analysis}

The follow-up rates in the consecutive and non-consecutive groups were $88.8 \%$ and $86.9 \%$ at 3 years and $75.9 \%$ and $78.6 \%$ at 5 years, respectively. In the consecutive group, $13(11.2 \%)$ patients experienced local failure and 44 (37.9\%) patients died, whereas in the non-consecutive group, 16 (19.0\%) patients experienced local failure and 35 (41.7\%) patients died (Table 2).

The unadjusted 5-year LC rate was $86.3 \%$ and $77.2 \%$ in the consecutive and non-consecutive group, respectively (log-rank test $\mathrm{p}=0.092$; HR $0.54 \%$, 95\% confidence interval [Cl] 0.26-1.11, p=0.095) (Fig. 2a). The unadjusted 5-year OS rate was 55.5\% and $51.8 \%$ in the consecutive and non-consecutive group, respectively (log-rank test $\mathrm{p}=0.39 ; \mathrm{HR} 0.82 \%, 95 \% \mathrm{Cl} 0.53-1.28, \mathrm{p}=0.39$ ) (Fig. 2b). After PS-weighting, consecutive treatment was associated with a significantly better LC (adjusted $\mathrm{HR} 0.30,95 \% \mathrm{Cl} 0.14-$ $0.65, p=0.002$ ) and OS (adjusted HR 0.56, 95\% Cl 0.34-0.91, p=0.019) than non-consecutive treatment (Additional file 1: Fig. S3). Furthermore, in the covariates-adjusted survival curves with PS-weighting (Additional file 1: Fig. S3), consecutive treatment was associated with significantly better LC (adjusted HR 0.36, 95\% Cl 0.18-0.72; $\mathrm{p}=0.004$ ) and OS (adjusted HR $0.57,95 \% \mathrm{Cl} 0.35-$ $0.93 ; p=0.024)$ than non-consecutive treatment. These results did not largely differ from that of a sensitivity analysis excluding patients with an OTT of 5 days (Additional file 1: Table S1).

\section{Discussion}


This study compared the outcomes in patients with early-stage NSCLC treated with consecutive or non-consecutive SBRT to assess the influence of OTT on tumor control. Our analysis showed that consecutive SBRT was associated with a marked improvement in LC compared with non-consecutive SBRT.

Our results might be explained by indirect cell death via tumor vascular damage, which is an emerging radiobiological concept in favor of high dose-per-fraction radiotherapy [18]. Song CW et al. [18,19] proposed that a single radiation dose higher than $10 \mathrm{~Gy}$ induces severe vascular damage in tumors and subsequently increases tumor hypoxia, leading to the death of hypoxic cells not associated with double-stranded DNA breakage. In this context, short treatment schedules may lead to greater vascular injury and better LC than long treatment schedules. Indeed, in murine models of lung cancer, Song C et al. [20] reported that while the tumor vasculature collapsed 6 hours after a single irradiation dose of $15 \mathrm{~Gy}$, the perfusion was restored only after 2 days. Further, Kelada et al. [21] reported in a clinical study with ${ }^{18} \mathrm{~F}$-fluoromisonidazole PET imaging for 6 NSCLC patients that the tumor hypoxic volume increased 2 days after a single irradiation dose of $18 \mathrm{~Gy}$ in $50 \%$ of patients, and the tumor hypoxic volume decreased in 4 days in $60 \%$ of patients with an elevated hypoxic volume. Moreover, our analysis showed that non-consecutive SBRT was associated with poor OS. Since most patients in our cohort were diagnosed with inoperable NSCLC and could not tolerate additional treatment for local failure owing to their age and comorbidities, it may be reasonable to consider that the increased local failure in the non-consecutive group led to the poor survival. We conducted an additional analysis on our data according to disease-specific survival and validated that the survival remained poor in the non-consecutive group (data not shown).

Alite et al. [13] reported that non-consecutive treatment (twice per week treatment, $>7$ days) was associated with better LC than consecutive treatment (daily treatment, $\leq 7$ days) in patients treated with SBRT of 50 or 60 Gy in 5 fractions in a retrospective study, which is contradictory to our results. They suggested that sufficient inter-fraction intervals allowed reoxygenation of hypoxic tumor cells, resulting in improved LC. It is well known that tumor hypoxia contributes to radiotherapy resistance [22,23]. A possible explanation for this discrepancy in results is the difference in OTT. The median OTT in the non-consecutive group was 14 days in their study but only 6 days in our study. Therefore, longer inter-fraction intervals than those used in this study may allow sufficient reoxygenation of hypoxic tumor cells and contribute to tumor cell death more effectively than vascular injury induced by short schedule SBRT. However, the previous reports, as well as our study, were limited by the retrospective study design and small sample size. Further research in a large population and comparative prospective trials are needed to determine the optimal OTT for SBRT.

This study had some limitations besides the retrospective study design and small sample size mentioned above. We performed IPTW and covariates-adjusted analysis to adjust for differences in baseline characteristics between the treatment groups. We included the calendar period of treatment as a covariate in the analysis because both classical and modern calculation algorithms were used in this study. However, our results may be potentially affected by biases from unobserved differences. The prescribed dose used in this study was lower than what is currently used worldwide. The isocenter prescription of 48 Gy in 4 fractions was the most common dose regimen in Japan, which is similar to $42 \mathrm{~Gy}$ in 4 fractions (BED10 $=86.1$ Gy) that covers $95 \%$ of the PTV [24]. The prescription dose was found to be a strong predictive factor for LC, and BED10 is currently recommended to be at least 100-105 Gy $[25,26]$. Therefore, if we administer a higher dose than that used in this study cohort, the observed difference between the consecutive and non-consecutive groups might decrease.

In conclusion, prolonged OTT appears to have a negative effect on the outcomes of patients with early-stage NSCLC treated with SBRT in a short treatment schedule. Further research comparing outcomes between consecutive and non-consecutive treatment schedule with longer OTT than that observed in this study is needed to determine the optimal OTT.

\section{Abbreviations}

SBRT, stereotactic body radiotherapy; LC, local control; NSCLC, non-small cell lung cancer. OTT, overall treatment time; BED, biologically effective dose; OS, overall survival; CT, computed tomography; ITV, internal target volume; GTV, gross tumor volume; PTV, planning target volume; 18F-FDG-PET/CT, 18F-fluorodeoxyglucose-positron emission tomography-CT; RTOG, Radiation Therapy Oncology Group; SUVmax, maximum standardized uptake value; PS, propensity score; IPTW, inverse probability of treatment weighting; $\mathrm{HR}$, hazard ratio; $\mathrm{Cl}$, confidence interval

Page 5/12 


\section{Declarations}

\section{Ethical approval and consent to participate}

This retrospective study was approved by the appropriate institutional review board (approval number 19164). All patients provided written informed consent for use of their data in clinical research before the administration of SBRT and had the opportunity to opt-out of the study.

\section{Consent for publication}

Not applicable

\section{Availability of data and materials}

The datasets used and/or analyzed during the current study are available from the corresponding author on reasonable request.

\section{Competing interests}

Toshiki Ikawa and Naoyuki Kanayama have served as consultants for Varian Medical Systems and may receive an honorarium from Varian Medical Systems. The other authors declare no competing interests.

\section{Funding}

This research did not receive any specific grant from funding agencies in the public, commercial, or not-for-profit sectors.

\section{Authors' Contributions}

TI conceptualized and designed the study; collected, curated, and analyzed the data, and composed the original draft of the manuscript. TTabuchi, SO and KO helped design the study and reviewed and edited the manuscript. KK, MM, TH, NK, KW and MT helped collect data and reviewed and edited the manuscript. TTeshima helped collect data, reviewed and edited the manuscript, and supervised the study. All authors read and approved the final manuscript.

\section{Acknowledgements}

We gratefully acknowledge Yoshihiro Ueda and Shingo Ohira (Department of Radiation Oncology, Osaka International Cancer Institute, Osaka, Japan) for their helpful advice. Additionally, we thank Editage (www.editage.jp) for English language editing.

\section{References}

1. Lo SS, Fakiris AJ, Chang EL, Mayr NA, Wang JZ, Papiez L, et al. Stereotactic body radiation therapy: a novel treatment modality. Nat Rev Clin Oncol. 2010;7:44-54. https://doi.org/10.1038/nrclinonc.2009.188.

2. Simone CB, Wildt B, Haas AR, Pope G, Rengan R, Hahn SM. Stereotactic body radiation therapy for lung cancer. Chest. 2013;143:1784-90. https://doi.org/10.1378/chest.12-2580.

3. Timmerman R, Paulus R, Galvin J, Michalski J, Straube W, Bradley J, et al. Stereotactic body radiation therapy for inoperable early stage lung cancer. JAMA. 2010;303:1070-6. https://doi.org/10.1001/jama.2010.261.

4. Nagata $Y$, Hiraoka M, Shibata T, Onishi H, Kokubo M, Karasawa $K$, et al. Prospective trial of stereotactic body radiation therapy for both operable and inoperable T1N0M0 non-small cell lung cancer: Japan clinical oncology group study JCOG0403. Int J Rad Oncol Biol Phys. 2015;93:989-96. https://doi.org/10.1016/j.jjrobp.2015.07.2278.

5. Videtic GMM, Donington J, Giuliani M, Heinzerling J, Karas TZ, Lally BE, et al. Stereotactic body radiation therapy for earlystage non-small cell lung cancer: executive summary of an ASTRO evidence-based guideline. Pract Rad Oncol. 2017;7:295301. https://doi.org/10.1016/j.prro.2017.04.014.

6. Kestin L, Grills I, Guckenberger M, Belderbos J, Hope AJ, Werner-Wasik M, et al. Dose-response relationship with clinical outcome for lung stereotactic body radiotherapy (SBRT) delivered via online image guidance. Radiother Oncol. 2014;110:499- 
504. https://doi.org/10.1016/j.radonc.2014.02.002.

7. Guckenberger M, Wulf J, Mueller G, Kreiger T, Baier K, Gabor M, et al. Dose-response relationship for image-guided stereotactic body radiotherapy of pulmonary tumors: relevance of 4D dose calculation. Int J Radiat Oncol Biol Phys. 2009;74:47-54. https://doi.org/10.1016/j.ijrobp.2008.06.1939.

8. Onishi H, Shirato H, Nagata Y, Hiraoka M, Fujino M, Gomi K, et al. Hypofractionated stereotactic radiotherapy (HypoFXSRT) for stage I non-small cell lung cancer: updated results of 257 patients in a Japanese multi-institutional study. J Thorac Oncol. 2007;2:S94-100. https://doi.org/10.1097/JT0.0b013e318074de34.

9. Grills IS, Hope AJ, Guckenberger M, Kestin LL, Werner-Wasik M, Yan D, et al. A collaborative analysis of stereotactic lung radiotherapy outcomes for early-stage non-small-cell lung cancer using daily online cone-beam computed tomography image-guided radiotherapy. J Thorac Oncol. 2012;7:1382-93. https://doi.org/10.1097/jto.0b013e318260e00d.

10. Fowler JF. The linear-quadratic formula and progress in fractionated radiotherapy. Br J Radiol. 1989;62:679-94. https://doi.org/10.1259/0007-1285-62-740-679.

11. Samson P, Rehman S, Juloori A, DeWees T, Roach M, Bradley J, et al. Local control for clinical stage I non-small cell lung cancer treated with five fraction stereotactic body radiation therapy is not associated with treatment schedule. Pract Radiat Oncol. 2018;8:404-13. https://doi.org/10.1016/j.prro.2018.04.004.

12. Stahl JM, Ross R, Harder EM, Mancini BR, Soulos PR, Finkelstein FE, et al. The effect of biologically effective dose and radiation treatment schedule on overall survival in stage I non-small cell lung cancer patients treated with stereotactic body radiation therapy. Int J Radiat Oncol Biol Phys. 2016;96:1011-20. https://doi.org/10.1016/j.jirobp.2016.08.033.

13. Alite F, Stang K, Balasubramanian N, Adams W, Shaikh MP, Small C, et al. Local control dependence on consecutive vs. nonconsecutive fractionation in lung stereotactic body radiation therapy. Radiother Oncol. 2016;121:9-14. https://doi.org/10.1016/j.radonc.2016.07.026.

14. Huang K, Dahele M, Senan S, Guckenberger M, Rodrigues GB, Ward A, et al. Radiographic changes after lung stereotactic ablative radiotherapy (SABR) - Can we distinguish recurrence from fibrosis? A systematic review of the literature. Radiother Oncol. 2012;102:335-42. https://doi.org/10.1016/j.radonc.2011.12.018.

15. Huang K, Senthi S, Palma DA, Spoelstra FOB, Warner A, Slotman BJ, et al. High-risk CT features for detection of local recurrence after stereotactic ablative radiotherapy for lung cancer. Radiother Oncol. 2013;109:51-77. https://doi.org/10.1016/j.radonc.2013.06.047.

16. Zhang X, Loberiza FR, Klein JP, Zhang M-J. A SAS macro for estimation of direct adjusted survival curves based on a stratified Cox regression model. Comput Meth Prog Bio. 2007;88:95-101. https://doi.org/10.1016/j.cmpb.2007.07.010.

17. Charlson ME, Pompei P, Ales KL, MacKenzie CR. A new method of classifying prognostic comorbidity in longitudinal studies: development and validation. J Chronic Dis. 1987;40:373-83.

18. Song CW, Glatstein E, Marks LB, Emami B, Grimm J, Sperduto PW, et al. Biological principles of stereotactic body radiation therapy (SBRT) and stereotactic radiation surgery (SRS): indirect cell death. Int J Radiat Oncol Biol Phys. 2019;S03603016:30291-3. https://doi.org/10.1016/j.ijrobp.2019.02.047.

19. Song CW, Lee Y-J, Griffin RJ, Park I, Koonce NA, Hui S, et al. Indirect tumor cell death after high-dose hypofractionated irradiation: implications for stereotactic body radiation therapy and stereotactic radiation surgery. Int J Radiat Oncol Biol Phys. 2015;93:166-72. https://doi.org/10.1016/j.ijrobp.2015.05.016.

20. Song C, Hong B-J, Bok S, Lee CJ, Kim YE, Jeon SR, et al. Real-time tumor oxygenation changes after single high-dose radiation therapy in orthotopic and subcutaneous lung cancer in mice: clinical implication for stereotactic ablative radiation therapy schedule optimization. Int J Radiat Oncol Biology Phys. 2016;95:1022-31.

https://doi.org/10.1016/j.ijrobp.2016.01.064.

21. Kelada OJ, Decker RH, Nath SK, Johung KL, Zheng MQ, Huang Y, et al. High single doses of radiation may induce elevated levels of hypoxia in early-stage non-small cell lung cancer tumors. Int J Radiat Oncol Biol Phys. 2018;102:174-83. https://doi.org/10.1016/j.ijrobp.2018.05.032.

22. Vaupel P, Mayer A. Hypoxia in cancer: significance and impact on clinical outcome. Cancer Metast Rev. 2007;26:225-39. https://doi.org/10.1007/s10555-007-9055-1. 
23. Brown JM, Wilson WR. Exploiting tumour hypoxia in cancer treatment. Nat Rev Cancer. 2004;4:437-47.

https://doi.org/10.1038/nrc1367.

24. Kawahara D, Ozawa S, Kimura T, Saito A, Nishio T, Nakashima T, et al. Marginal prescription equivalent to the isocenter prescription in lung stereotactic body radiotherapy: preliminary study for Japan Clinical Oncology Group trial (JCOG1408). J Radiat Res. 2017;58:149-54. https://doi.org/10.1093/jrr/rrw096.

25. Guckenberger M, Andratschke N, Dieckmann K, Hoogeman MS, Hoyer M, Hurkmans C, et al. ESTRO ACROP consensus guideline on implementation and practice of stereotactic body radiotherapy for peripherally located early stage non-small cell lung cancer. Radiother Oncol. 2017;124:11-7. https://doi.org/10.1016/j.radonc.2017.05.012.

26. Boily G, Filion É, Rakovich G, Kopek N, Tremblay L, Samson B, et al. Stereotactic ablative radiation therapy for the treatment of early-stage non-small-cell lung cancer: CEPO review and recommendations. J Thorac Oncol. 2015;10:872-82.

https://doi.org/10.1097/jto.0000000000000524

\section{Tables}


Table 1. Patient characteristics per treatment groups and standardized mean differences before and after propensity score weighting

\begin{tabular}{|c|c|c|c|c|c|c|c|}
\hline \multirow[b]{2}{*}{ Characteristic } & \multicolumn{2}{|c|}{ Unweighted, n (\%) } & \multirow[t]{2}{*}{$\begin{array}{l}\text { P- } \\
\text { value* }^{*}\end{array}$} & \multicolumn{2}{|c|}{$\begin{array}{l}\text { Propensity score-weighted, } \\
\%\end{array}$} & \multicolumn{2}{|c|}{$\begin{array}{l}\text { Standardized mean } \\
\text { difference }\end{array}$} \\
\hline & $\begin{array}{l}\text { Consecutive } \\
n=116\end{array}$ & $\begin{array}{l}\text { Non- } \\
\text { consecutive } \\
\mathrm{n}=84\end{array}$ & & Consecutive & $\begin{array}{l}\text { Non- } \\
\text { consecutive }\end{array}$ & Unweighted & $\begin{array}{l}\text { Propensity } \\
\text { score- } \\
\text { weighted }\end{array}$ \\
\hline Age (years) & & & 0.65 & & & 0.13 & 0.041 \\
\hline $50-69$ & $14(12.1)$ & $11(13.1)$ & & 12.6 & 11.6 & & \\
\hline $70-79$ & $46(39.7)$ & $38(45.2)$ & & 41.1 & 40.2 & & \\
\hline $80-90$ & $56(48.3)$ & $35(41.7)$ & & 46.3 & 48.2 & & \\
\hline Sex & & & 0.34 & & & 0.16 & 0.013 \\
\hline Female & $29(25.0)$ & $27(32.1)$ & & 27.1 & 27.7 & & \\
\hline Male & $87(75.0)$ & $57(67.9)$ & & 72.9 & 72.3 & & \\
\hline Histological type & & & 0.72 & & & 0.12 & 0.089 \\
\hline Adenocarcinoma & $51(44.0)$ & $38(45.2)$ & & 44.9 & 41.4 & & \\
\hline $\begin{array}{l}\text { Squamous cell } \\
\text { carcinoma }\end{array}$ & $26(22.4)$ & 15 (17.9) & & 21.4 & 24.8 & & \\
\hline $\begin{array}{l}\text { Non-biopsy- } \\
\text { proven }\end{array}$ & 39 (33.6) & 31 (36.9) & & 33.7 & 33.8 & & \\
\hline Tumor size & & & 0.28 & & & 0.23 & 0.030 \\
\hline $1 \mathrm{a}(\leq 2 \mathrm{~cm})$ & $63(54.3)$ & $38(45.2)$ & & 48.8 & 48.0 & & \\
\hline $\begin{array}{c}1 \mathrm{~b} \\
\mathrm{~cm})\end{array}(>2 \mathrm{~cm}, \leq 3$ & $32(27.6)$ & $32(38.1)$ & & 33.0 & 32.7 & & \\
\hline $\begin{array}{l}2 \mathrm{a}(>3 \mathrm{~cm}, \leq 5 \\
\mathrm{cm})\end{array}$ & $21(18.1)$ & $14(16.7)$ & & 18.1 & 19.3 & & \\
\hline $\begin{array}{l}\text { Pretreatment } \\
\text { SUVmax }\end{array}$ & & & 0.37 & & & 0.20 & 0.060 \\
\hline$\leq 5$ & $61(52.6)$ & $52(61.9)$ & & 56.4 & 54.2 & & \\
\hline$>5$ & $47(40.5)$ & $26(31.0)$ & & 36.9 & 39.8 & & \\
\hline Unknown & $8(6.9)$ & $6(7.1)$ & & 6.7 & 6.0 & & \\
\hline Tumor location & & & 0.62 & & & 0.09 & 0.004 \\
\hline Lower lobe & $35(30.2)$ & $29(34.5)$ & & 33.0 & 32.9 & & \\
\hline $\begin{array}{l}\text { Upper/Middle } \\
\text { lobe }\end{array}$ & $81(69.8)$ & $55(65.5)$ & & 67.0 & 67.1 & & \\
\hline $\begin{array}{l}\text { Charlson } \\
\text { comorbidity } \\
\text { index [17] }\end{array}$ & & & 0.30 & & & 0.18 & 0.012 \\
\hline $0-2$ & 90 (77.6) & $71(84.5)$ & & 80.7 & 80.2 & & \\
\hline$>2$ & $26(22.4)$ & $13(15.5)$ & & 19.3 & 19.8 & & \\
\hline $\begin{array}{l}\text { Prior history of } \\
\text { surgery or }\end{array}$ & & & 0.23 & & & 0.19 & 0.029 \\
\hline
\end{tabular}


radiotherapy for

lung cancer

\begin{tabular}{|c|c|c|c|c|c|c|c|}
\hline No & $90(77.6)$ & $58(69.0)$ & & 77.1 & 78.3 & & \\
\hline Yes & $26(22.4)$ & $26(31.0)$ & & 22.9 & 21.7 & & \\
\hline $\begin{array}{l}\text { Calendar period } \\
\text { of treatment }\end{array}$ & & & $\begin{array}{l}< \\
0.001\end{array}$ & & & 0.62 & 0.025 \\
\hline 2007-2008 & $50(43.1)$ & 14 (16.7) & & 32.0 & 33.1 & & \\
\hline $2009-2010$ & $32(27.6)$ & $40(47.6)$ & & 37.2 & 36.3 & & \\
\hline $2011-2013$ & $34(29.3)$ & 30 (35.7) & & 30.9 & 30.6 & & \\
\hline $\begin{array}{l}\text { History of } \\
\text { smoking }\end{array}$ & & & 0.20 & & & 0.21 & 0.014 \\
\hline No & $18(15.5)$ & $20(23.8)$ & & 20.3 & 20.9 & & \\
\hline Yes & $98(84.5)$ & 64 (76.2) & & 79.7 & 79.1 & & \\
\hline
\end{tabular}

*P-values were calculated before propensity score weighting.

SUVmax, maximum standardized uptake value

\begin{tabular}{|lllll|}
\hline \multicolumn{4}{|l}{ Table 2. Crude event rates of local failure and death according to overall treatment time } \\
\hline Overall treatment time (days) & $\begin{array}{l}\text { Local failure } \\
\text { Events/n }\end{array}$ & $\%$ & $\begin{array}{l}\text { Death } \\
\text { Events/n }\end{array}$ & $\%$ \\
\hline 4 & $11 / 107$ & 10.3 & $40 / 107$ & 37.4 \\
\hline 5 & $2 / 9$ & 22.2 & $4 / 9$ & 44.4 \\
\hline 6 & $10 / 56$ & 17.9 & $24 / 56$ & 42.9 \\
\hline 7 & $2 / 13$ & 15.4 & $3 / 13$ & 23.1 \\
\hline 8 & $2 / 9$ & 22.2 & $5 / 9$ & 55.6 \\
\hline 9 & $0 / 2$ & 0 & $1 / 2$ & 50 \\
\hline 10 & $2 / 4$ & 50 & $2 / 4$ & 50 \\
\hline $\begin{array}{l}\text { Consecutive } \\
(4 \text { or } 5 \text { days) }\end{array}$ & $13 / 116$ & 11.2 & $44 / 116$ & 37.9 \\
\hline $\begin{array}{l}\text { Non-consecutive } \\
(6-10 \text { days) }\end{array}$ & $16 / 84$ & 19.0 & $35 / 84$ & 41.7 \\
\hline
\end{tabular}

\section{Figures}




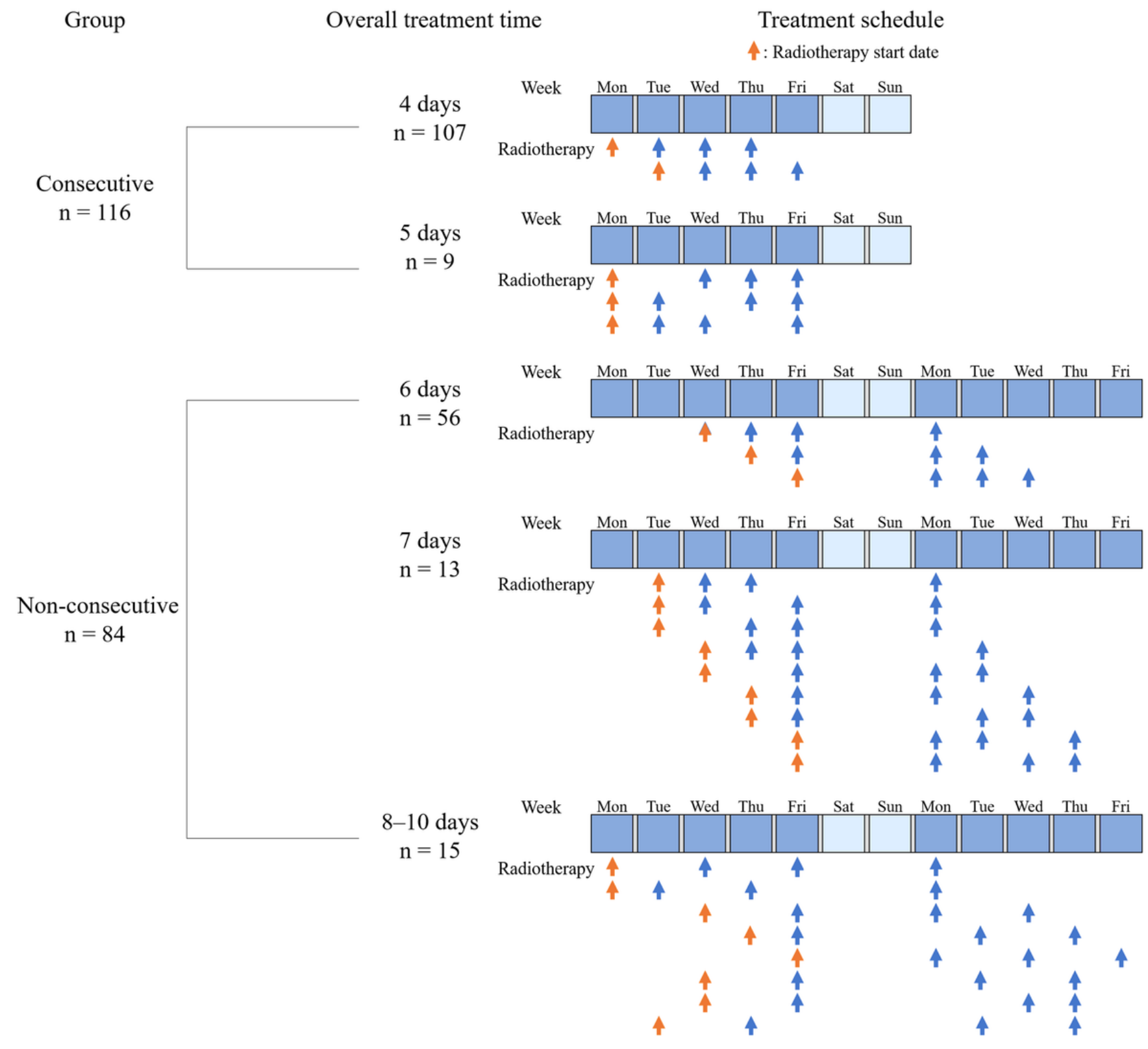

Figure 1

Graphical depiction of the stereotactic body radiotherapy schedules for the consecutive and non-consecutive treatment groups 

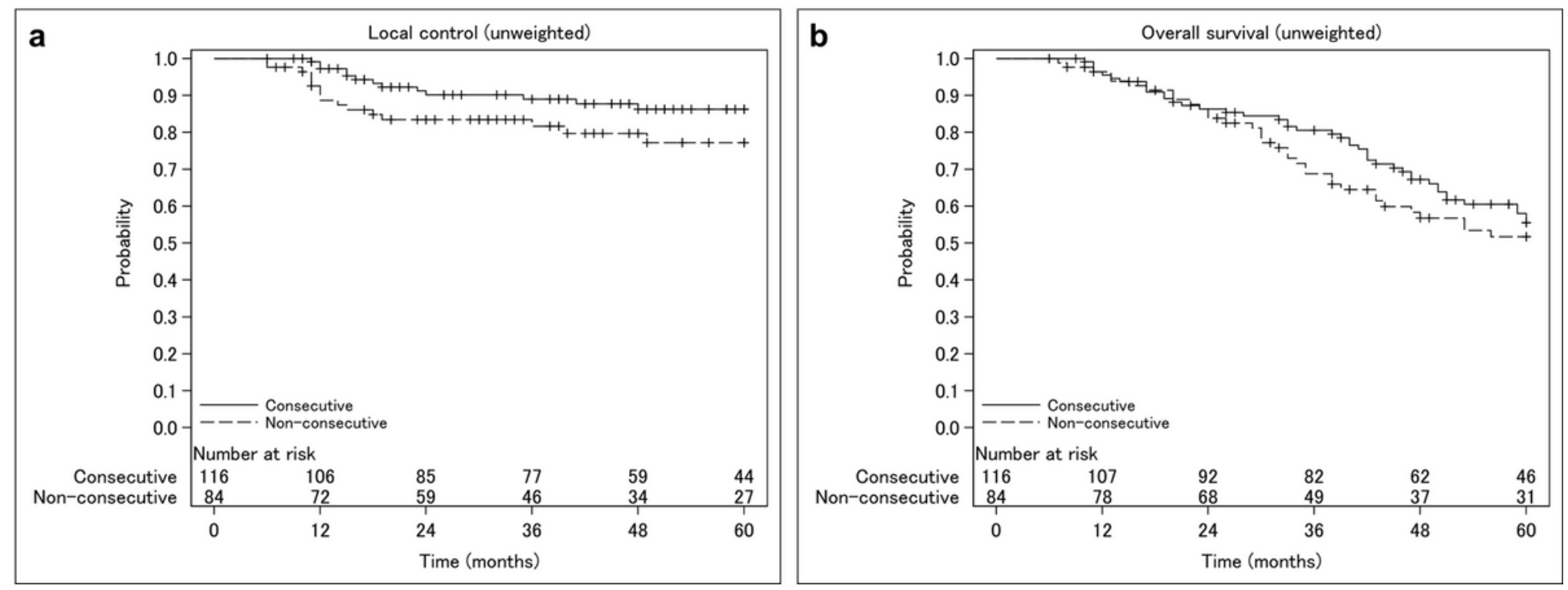

Figure 2

Unweighted local control (a) and overall survival (b) Kaplan-Meier curves in the treatment groups

\section{Supplementary Files}

This is a list of supplementary files associated with this preprint. Click to download.

- Additionalfile1.docx 